\title{
Antarctica on foot: the energy expended to walk, ski and man-haul
}

\author{
L. G. Halsey ${ }^{1} \cdot$ R. Lambert ${ }^{2} \cdot$ P. Collins ${ }^{1} \cdot$ A. Newnham ${ }^{1} \cdot$ A. Kumar ${ }^{3}$. \\ C. O'Driscoll ${ }^{1}$ M. A. Stroud ${ }^{4}$
}

\begin{abstract}
Polar exploration often involves travelling on foot and thus is physically intensive, with long-term excursions typically resulting in weight loss. Few studies have investigated the energy expended under such circumstances. Here, we present a range of prediction equations for estimating metabolic rate from heart rate or accelerometry data for specific activities including skiing and man-hauling which can be applied to either short- or long-term excursions. We also use some of these equations to estimate the energy expended undertaking various activities by a team of explorers while attempting to traverse the Antarctic continent during the austral winter of 2013 (as part of the White Mars Project during The Coldest Journey). Calibration equations based on either accelerometry data (from which overall dynamic body acceleration, ODBA, is derived) or heart rate showed good relationships with rate of oxygen consumption, particularly when person height was included. Periods of skiing and man-hauling on The Coldest Journey were estimated to be more energetically demanding (30.0 and $31.1 \mathrm{~kJ} \mathrm{~min}^{-1}$, respectively) than walking $\left(24.9 \mathrm{~kJ} \mathrm{~min}^{-1}\right)$, or other outdoor work $\left(21.9 \mathrm{~kJ} \mathrm{~min}^{-1}\right)$.
\end{abstract}

L. G. Halsey

1.halsey@ roehampton.ac.uk

1 Department of Life Sciences, University of Roehampton, Holybourne Avenue, London SW15 4JD, UK

2 Department of Orthopaedic Surgery, Royal Infirmary of Edinburgh, Little France Crescent, Edinburgh EH16 4SA, UK

3 Department of Physiologie, University of Fribourg, 1700 Fribourg, Switzerland

4 National Institute for Health Research Biomedical Research Centre in Nutrition, Southampton University Hospitals Trust, Southampton SO16 6YD, UK
Estimates of energy expenditure during The Coldest Journey were similar to measures obtained in previous, comparative scenarios. We hope that future expeditions to Antarctica will use these prediction equations to further our understanding of the energy costs of exploring Antarctica and the nutritional requirements needed to guard against emaciation.

Keywords Accelerometry - Heart rate - Metabolic rate Oxygen consumption · Treadmill · Ski machine ·

Antarctica

\section{Introduction}

Explorations on foot in the polar regions have often resulted in emaciation (Marshall 1943; Stroud 1993; Stroud et al. 1996), with effects ranging from ill health to death (Scott 2008). The early days of man-hauling explorations of Antarctica were beset by a lack of understanding about the amount of energy expended on such trips (Marshall 1943; Halsey and Stroud 2012), leading to an underestimation of the nutritional content of foodstuffs needed to sustain body mass. In more recent times, average daily energy expenditures during unaided explorations of Antarctica have been estimated, both via doubly labelled water and dietary intake records in conjunction with recorded changes in body condition (Stroud et al. 1997). Studies conducted in the Arctic and Antarctic concluded that for longer-duration expeditions, the amount of food required to support the extraordinary energy requirements simply cannot be transported on foot (Stroud 1987; Stroud et al. 1993, 1997). Antarctic explorations without mechanical support therefore inevitably result in the protagonists inflicting on themselves an exercise-induced 'starvation diet' (Halsey and Stroud 2012). 
A strong understanding about the rates of energy expenditure during unaided travel is therefore particularly pertinent in the context of health in Antarctica, yet the previously used methods have only been able to return estimates of overall energy expenditure across many days. These methods have not been suitable for estimating the costs of specific activities undertaken on the continent such as skiing and man-hauling a pulk. Such detail about energy expenditure can, for example, provide important insights into activities that are particularly conducive to body mass loss. In the March of the austral winter of 2013, five men set off inland from Crown Bay on the edge of Antarctica in an attempt to make the first crossing of the continent during the austral winter. This expedition provided an opportunity to estimate energy costs for a variety of activities undertaken by Antarctic explorers. After travelling $335 \mathrm{~km}$, walking and skiing alongside driving two modified tracked bulldozers which each pulled a living caboose/indoor shelter, they desisted from further progress having entered an unmapped ice field. The expedition established a camp and remained in place until late September of that year. During this 4-month period in one location, exercise included roundtrips from the camp involving walking, skiing and man-hauling. The men then travelled back towards the coast, ending their land journey on Antarctica near Princess Elizabeth Station in November 2013, flying home a few weeks later.

Suitably calibrated, measures of acceleration and/or heart rate $\left(f_{\mathrm{H}}\right)$ recorded on data loggers attached to people are known to provide valid, quantifiable estimates of their energy expenditure during periods of activity at a range of temporal scales, at least at the group level (Boothby 1915; Cavagna et al. 1963; Halsey et al. 2008, 2011; Green 2011). Both these proxies and the associated techniques needed to measure them inevitably have limitations (Eston et al. 1998; Bouchard and Trudeau 2008; Halsey 2011; Halsey et al. 2011). While $f_{\mathrm{H}}$ is usually better related than accelerometry data to energy expenditure in low-activity contexts, $f_{\mathrm{H}}$ can be affected by mental state (Carroll et al. 1986), and neither proxy is clearly better during periods of higher activity (Halsey et al. 2008; Green et al. 2009). Accelerometry data tend to be more tractable to record than $f_{\mathrm{H}}$ away from the laboratory because measures of $f_{\mathrm{H}}$ are frequently inaccurate or intermittent if the logger electrodes do not provide a consistently clear ECG. In view of these concerns within the physically and mentally demanding environment of Antarctica, we therefore elected to provide each of the five men on this expedition with a tri-axial acceleration data logger (accelerometer), which they wore on certain days of the journey (typically days when they anticipated undertaking relatively long periods of defined activity). Calibration experiments were conducted at the University of Roehampton involving simulated walking, skiing and man-hauling in the laboratory, while simultaneously measuring rates of oxygen consumption $\left(\dot{V}_{\mathrm{O}_{2}}\right)$ and recording the acceleration measured on an instrumented accelerometer. Under these laboratory conditions, it was also straightforward to measure $f_{\mathrm{H}}$ and so compare the precision of the two energy expenditure proxies in these particular contexts and develop prediction equations based on both $f_{\mathrm{H}}$ and accelerometry data. Using the acceleration data prediction equations obtained from the laboratory in combination with the data collected in the field (Fig. 1), we were able to provide estimates of the energy costs of specific activities associated with travel in Antarctica.

\section{Methods}

The experimental protocols were assessed and approved by the Ethics Committee at the University of Roehampton.
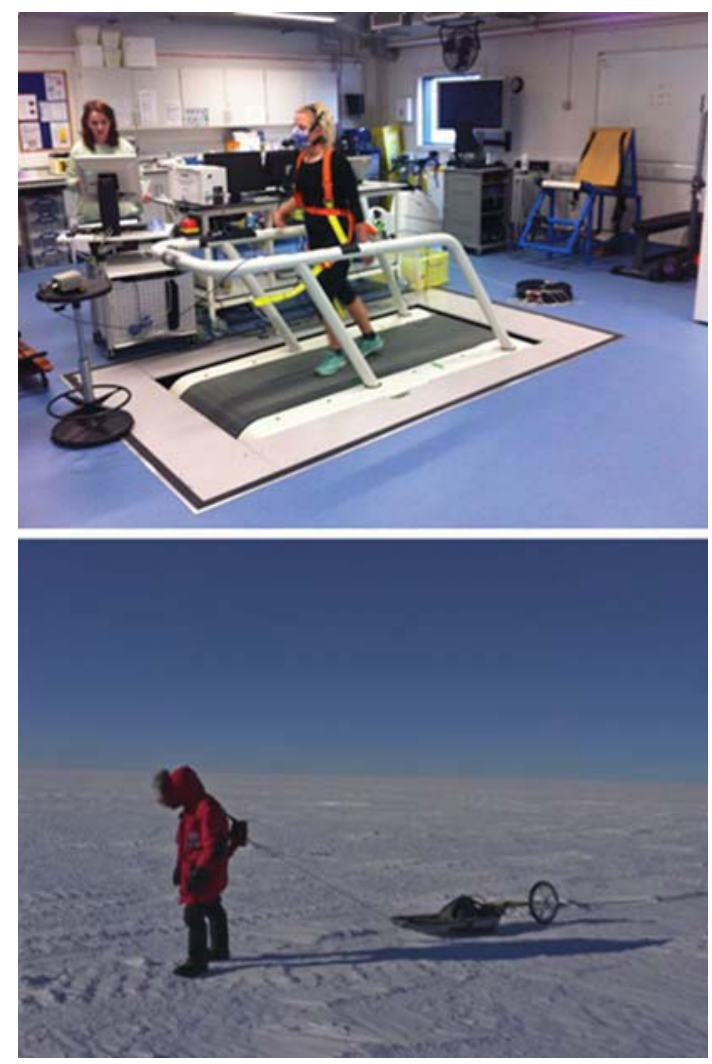

Fig. 1 Upper panel laboratory-based calibrations of overall dynamic body acceleration (ODBA) and heart rate as proxies of rate of oxygen consumption. The participant is walking on a treadmill while pulling against fixed weights to simulate man-hauling. A strain gauge records the force applied between the back of the harness worn by the participant and the rope connecting the harness to the weight. The strain is presented to the participant on a digital display such that they can maintain a fairly constant pulling effort. Lower panel a member of The Coldest Journey team man-hauling a pulk in Antarctica 


\section{Laboratory calibrations}

\section{Participants and experiments}

Ten men and four women encompassing a range of fitness levels and statures participated. Before the start of the experiments, the participants' weights $(77.1 \pm 1 \mathrm{SD}$ : $14.7 \mathrm{~kg})$ and heights $(173.6 \pm 8.2 \mathrm{~cm})$ were recorded. Participants did not have any cardiac or metabolic disorders and were not currently taking any medication for chronic ailments. Informed consent was obtained from all participants, and a PAR-Q questionnaire was completed before the experiments began.

The experiments consisted of walking on a treadmill (Woodway Ergo ELG 70) and skiing on a ski machine (Nordic Track Classic Pro) at various speeds in a randomised order. $\dot{V}_{\mathrm{O}_{2}}\left(\mathrm{~mL} \min ^{-1}\right)$ and $f_{\mathrm{H}}$ (beats $\left.\min ^{-1}\right)$ were recorded along with the acceleration $(g)$ experienced by an accelerometer data logger attached to the participant's sternum. Heart rate was measured using a monitor (Polar CS100 wearlink and transmitter, Polar Electro) recording at $0.2 \mathrm{~Hz}$. Acceleration was measured using a Model X6-2 tri-axial data logger (Gulf Coast Data Concepts) recording 0 to $\pm 6 \mathrm{~g}$ at $10 \mathrm{~Hz}$ and 12-bit resolution. During the experiments, the temperature of the laboratory ranged between 22 and $25{ }^{\circ} \mathrm{C}$. Participants were required to undertake a short practice at ski machine skiing prior to the experiments.

The treadmill experiment consisted of walking at various speeds (between 2 and $8 \mathrm{~km} \mathrm{~h}^{-1}$, inclusive) on a treadmill at $0^{\circ}$ incline. A range of walking speeds were repeated during which the participant pulled against a stationary weight placed behind the treadmill to simulate pulling along a mass while walking ('man-hauling'). The stationary weight was attached to a strain gauge providing a digital read-out that the participants could see. The order of the walking conditions (denoted by walking speed and whether the participant was pulling against a weight or not) was randomised. The participants experienced each condition for a minimum of three minutes, more typically four minutes, and rested for as long as they wished when necessary between conditions, though participants typically took no break or just a few seconds of rest between them. The range and number of walking speeds undertaken varied between participants; however, the maximum speed was never greater than a natural walking pace. During the mass-pulling conditions, the participants pulled against stacked weights (Fig. 1) to simulate hauling a loaded sledge. The participants wore a harness, to the back of which a strain gauge (Novatech F256TBROKN) was attached; the other end was attached to the weights via a guy rope. The digital read-out from the strain gauge was purposely in view for all participants to help them maintain a consistent measured strain $(\mathrm{kg})$ throughout the condition. The range of recorded strains across all participants was 2-12 kg and varied between individuals although ranges for individual participants varied; participants pulled up to a force that they were able to maintain without excessive excursion, for several minutes.

The ski machine experiment consisted of skiing at two distinct speeds and two distinct resistance levels set on the machine, resulting in four conditions. A digital read-out reporting the rate of revolutions of a flywheel on the ski machine (revolution $\min ^{-1}$ ) was in view of the participants such that they could attempt to maintain a consistent speed throughout each condition. The two speeds that each participant attempted to maintain varied and were somewhat self-selected since participants varied in terms of the skiing speeds that they were best able to maintain. The majority of participants were aided in maintaining a speed by skiing in time with a metronome set at $0.5 \mathrm{~Hz}$, and only some participants used the hand pulls, while others held onto a horizontal bar. Where the metronome was employed, as their two speeds participants undertook both half a ski cycle (each foot switches position between forwards and backwards of the body) and a whole ski cycle (each foot returns to its initial position) per $2 \mathrm{~s}$.

\section{Physiological measurements}

$\dot{V}_{\mathrm{O}_{2}}$, rate of carbon dioxide output and respiratory exchange ratio (RER) were measured using a gas analyser (Oxycon Pro, Jaeger), incorporating an oxygen paramagnetic analyser and a carbon dioxide infrared analyser. Values were initially measured at 'body pressure and temperature, saturated' (BPTS) and converted to 'standard temperature and pressure, dried' (STPD) using the Haldane transformation. This system involved continuous monitoring of breath-by-breath measurements utilising a lightweight and low-resistance facemask from which samples of the expired air were drawn through tubing at a constant rate. This breath-by-breath data provided confirmation that the participant reached steady state during each condition and RER did not reach 1 (indicating that anaerobic metabolism was negligible). The $f_{\mathrm{H}}$ monitor was attached to the chest of the participant just above the sternum with a strap while the acceleration logger was attached to the sternum, i.e. just below the $f_{\mathrm{H}}$ monitor, in its vertical orientation, using adhesive tape. The acceleration logger did not noticeably move relative to the body during exercise, ensuring that the logger recorded only acceleration attributable to body movement.

During the experiments, means of $\dot{V}_{\mathrm{O}_{2}}, f_{\mathrm{H}}$ and measures of acceleration in three axes were recorded over the final 
minute or thirty seconds of each condition based on visualisation of the breath-by-breath $\dot{V}_{\mathrm{O}_{2}}$ data indicating when physiological steady state had been reached (Meijer et al. 1989; Terrier et al. 2001; Achten et al. 2002). This is usually after around 2-3 min, but can be less in reasonably fit individuals (Whipp and Wasserman 1972; Chilibeck et al. 1996; ACSM 2013), particularly when rest between conditions is relatively short. Where estimated $\dot{V}_{\mathrm{O}_{2}}$ was converted to rate of energy expenditure, it was assumed that $1 \mathrm{~L} \mathrm{O}_{2}=4.8 \mathrm{kcal}=20.1 \mathrm{~kJ}$ (a blend of macronutrient utilisation; Schmidt-Nielsen 1997).

\section{Analysis of laboratory data}

Movement of body parts results in movement of the body's centre of mass, and the latter has been shown to correlate with $\dot{V}_{\mathrm{O}_{2}}$ (Halsey et al. 2009b). Raw acceleration data from an instrumented acceleration data logger encapsulate two gravitational components: static acceleration due to gravity and dynamic acceleration due to body movement (Gleiss et al. 2011). Thus, the acceleration of the body's centre of mass due to the movement of its body parts can be determined by recording acceleration data at a fixed point on the body such as the torso and then from those data extracting an approximation of absolute $g$ due only to dynamic acceleration of the body in each of the three dimensions (Gleiss et al. 2011; Halsey et al. 2011). This extraction was achieved in the present study by removing an approximation of the static acceleration calculated via a running mean, which spanned 30 data points, i.e. $3 \mathrm{~s}$, a suitable smoothing duration for many exercise scenarios (Green et al. 2009; Halsey et al. 2009a). The resulting absolute dynamic values were then summed to produce 'overall dynamic body acceleration', ODBA (see Wilson et al. 2006 for more details), for relating to $\dot{V}_{\mathrm{O}_{2}}$.

General linear models (GLMs), fitted using maximum $\log$ likelihood, were generated to investigate the relationships between $\dot{V}_{\mathrm{O}_{2}}$ and ODBA, and $\dot{V}_{\mathrm{O}_{2}}$ and $f_{\mathrm{H}}$. These models also included a categorical variable, set with a random intercept, that identified each participant ('Participant ID') to recognise that the data were repeated measures for each participant. Initial models investigated also included a categorical variable 'Exercise type', as a fixed factor, to recognise the association of each data point with walking, man-hauling or skiing.

Specifically, for both ODBA and $f_{\mathrm{H}}$ separately, two mixed linear models were generated and compared using Akaike's information criterion (AIC) as a measure of model fit (Burnham and Anderson 2010). The first model included exercise type and the interaction between exercise type and ODBA or $f_{\mathrm{H}}$ (e.g. $\dot{V}_{\mathrm{O}_{2}} \sim$ ODBA + Exercise type + Participant ID [random $]+$ ODBA $\times$ Exercise type). The second model did not include exercise type (e.g. $\dot{V}_{\mathrm{O}_{2}} \sim f_{\mathrm{H}}+$ Participant ID [random]) in recognition of the possible scenario that logger data are available without accompanying information on exercise type. These models were assessed, and consequently prediction equations were generated, suitable for application to a group of individuals for whom morphometric data are not available. Information was also provided to calculate the precision of the prediction equations as and when applied to a different group of people from those used in the calibration experiments (such as the five men of the expedition team documented in the present study). Specifically, the standard errors of the estimate (SEE) and $95 \%$ confidence intervals of the estimate of $\dot{V}_{\mathrm{O}_{2}}$ can be calculated, and also then the relative standard errors of the estimate (the relative size of the estimate error associated with estimated $\dot{V}_{\mathrm{O}_{2}}$, calculated as SEE/estimated $\dot{V}_{\mathrm{O}_{2}}$ as a \%). When a prediction equation is applied to a new group of individuals, the precision of the estimate of $\dot{V}_{\mathrm{O}_{2}}$ is affected by not only the predictive power of the equation but also the number of participants and number of ODBA or $f_{\mathrm{H}}$ data points input to the equation. As explained in Green (2011), prediction equations derived from one group of individuals may well not be precise when applied to a new, single individual and instead are suitable for estimating the mean rate of energy expenditure of a group. To illustrate these issues, the $95 \%$ confidence intervals and relative SEEs associated with estimates derived from ODBA in the present study were calculated for three scenarios in terms of the number of people in the expedition of interest and the amount of data collected, in order to illustrate the approximate span of prediction preciseness that can be expected. For more information and details of the calculations employed, see Green et al. (2001).

Some individual variations in $\dot{V}_{\mathrm{O}_{2}}$-ODBA relationships and $\dot{V}_{\mathrm{O}_{2}}-f_{\mathrm{H}}$ relationships are likely to be caused by differences in body mass and/or height. However, the inclusion of morphometric data in a prediction equation is not straightforward, since such values are typically fixed, or vary little, for each participant, leaving little to no variance for a model to partition. As described in Halsey et al. (2007) and applied in Lyons et al. (2013), one option is to regress the individual estimate for each participant associated with the initial prediction models against morphometric measures and include the relationship in the $\dot{V}_{\mathrm{O}_{2}}$ prediction equation. In the present study, the individual estimates associated with both the ODBA models and the $f_{\mathrm{H}}$ models were well related to height (ODBA, $R^{2}=0.57$; $\left.f_{\mathrm{H}}, R^{2}=0.54\right)$. They were slightly less well related to weight (ODBA, $\left.R^{2}=0.44 ; f_{\mathrm{H}}, R^{2}=0.45\right)$. Since height and weight are related to each other while height is 
particularly easy to measure in the field, further $\dot{V}_{\mathrm{O}_{2}}$ prediction equations were generated by adding a linear description of individual variance against height to the previous equations.

GLM models were built and associated analysis undertaken in R v.3 (R Development Core Team 2013), including use of the 'nlme' package for generating linear mixed models (Pinheiro et al. 2014) and the 'MuMIn' package for calculating pseudo- $R^{2}$ values for those models (Barton 2013), while SPSS was used to provide parameter estimates for each individual participant in the laboratory experiments (IBM SPSS Statistics v.21).

\section{Field study}

The Coldest Journey (http://www.thecoldestjourney.org/), otherwise known as the Trans-Antarctic Winter Traverse, was a year-long expedition that aimed to make the first crossing of Antarctica during the polar winter. The expedition was vehicle-based, using tracked bulldozers to pull two 'cabooses', modified shipping containers on skis, which housed the team and their equipment during the attempt. The team ultimately consisted of five men. A further objective of the expedition was to carry out a programme of scientific research. Human sciences research during the expedition comprised many distinct studies into human physiology and psychology, including the study we report herein. This scientific programme was entitled The White Mars Project since conditions in Antarctica (including isolation, confinement, low temperatures and darkness) are often used as an analogue for space travel. For example, from the period of the 21st March to the 21st September, average ambient air temperature in the vicinity of the men was $-37{ }^{\circ} \mathrm{C}$ (average barometric pressure was 704 mbar).

The men set off inland from Crown Bay on the edge of Antarctica $\left(70^{\circ} 06^{\prime} 14.9^{\prime \prime} \mathrm{S}, 022^{\circ} 56^{\prime} 11.8^{\prime \prime} \mathrm{E}\right)$ on the $22 \mathrm{nd}$ March 2013 but on the 9 May, after travelling $335 \mathrm{~km}$ to Camp W24 $\left(72^{\circ} 54^{\prime} 20.4^{\prime \prime} \mathrm{S}, 023^{\circ} 35^{\prime} 08.0^{\prime \prime} \mathrm{E}\right.$, altitude 2 $824 \mathrm{~m}$ ), they desisted from further progress having entered a dangerous, unmapped ice crevasse field. For the following 4-month period, the men were sometimes sedentary, although daily checks of the campsite and equipment together with outside exercise when conditions allowed, provided a fair amount of activity. Indeed, the majority of data collected for the present study was obtained during this period, during which the men undertook the same forms of travel as those undertaken while travelling to the ice field. On the 24 September, the men started travelling back towards the coast, reaching Princess Elizabeth Station $\left(71^{\circ} 57^{\prime} 04.4^{\prime \prime} \mathrm{S}, 023^{\circ} 20^{\prime} 10.2^{\prime \prime} \mathrm{E}\right.$, altitude $\left.1367 \mathrm{~m}\right)$ on the $1 \mathrm{st}$ November.
During their attempted crossing of Antarctica, all five team members periodically wore an accelerometer (Model X16-2 tri-axial data logger; Gulf Coast Data Concepts). The logger recorded 0 to $\pm 16 g$ at $12 \mathrm{~Hz}$ and 15-bit resolution and was placed vertically in the top pocket of the garments being worn; remaining space in the pocket was stuffed with paper to secure the position of the logger from additional movement. Therefore, location of the instrumented logger was reasonably replicated between laboratory and field participants. Team members wore the loggers during a range of activities and kept diaries documenting these. For each period that a team member wore a logger, the major activity or activities were recorded, along with the team member's body mass. Activities were categorised for analysis subsequent to the field data being sent to the University of Roehampton once the expedition had finished. The categories employed were: walking, skiing, man-hauling and working outside. In most cases the entire data set apart from the first 10 min was used to represent the activity or activities assigned to that recording period; the first 10 min typically included the attaching of the logger directly after it had started recording. Those data sets were used to calculate group mean ODBA values for each activity, which in turn were used to estimate mean $\dot{V}_{\mathrm{O}_{2}}$ (and associated measures of estimate error).

All data used in this study are available upon request.

\section{Results}

\section{Laboratory data}

On occasion a participant did not undertake a particular exercise type, or the data did not record properly for particular conditions. Investigation of the veritable data for each participant indicated relationships between $\dot{V}_{\mathrm{O}_{2}}$ and both ODBA and $f_{\mathrm{H}}$ (Fig. 2). All data for all participants were included in the GLMs. In the case of both the ODBAbased and $f_{\mathrm{H}}$-based models, consideration of the AIC and $R^{2}$ values together suggested that while the better model fit of the candidate models included the factor exercise type, this factor improved the model fits only marginally (Table 1). Thus, the models including the factor exercise type are not considered further; however, activity-specific predication equations are also applied to the field data in the present study, and are reported in Table 2. The models not including exercise type represent $\dot{V}_{\mathrm{O}_{2}}\left(\mathrm{~mL} \mathrm{O}_{2} \min ^{-1}\right)$ prediction equations for people in general undertaking a range of typical Antarctic activities, where ODBA is in $g$ and $f_{\mathrm{H}}$ is in beats $\min ^{-1}$ : 
Estimated $\dot{V}_{\mathrm{O}_{2}}=1879.2 \times \mathrm{ODBA}+711.0$

Estimated $\left.\dot{V}_{\mathrm{O}_{2}}=25.0 \times f_{\mathrm{H}}\right)-1323.6$

$95 \%$ confidence intervals and relative SEEs for Eq. 1a are presented in Fig. 3. For situations where person height $(\mathrm{cm})$ is available, the augmented prediction equations are:

$$
\begin{aligned}
\text { Estimated } \dot{V}_{\mathrm{O}_{2}}= & (1879.2 \times \mathrm{ODBA}+711.0) \\
& +(27.0 \times \text { height }-4881.9)
\end{aligned}
$$

Estimated $\dot{V}_{\mathrm{O}_{2}}=\left(25.0 \times f_{\mathrm{H}}-1323.6\right)$

$$
+(39.2 \times \text { height }-6729.8)
$$

Comparison of the predictive power of Eqs. $2 \mathrm{a}$ and $2 \mathrm{~b}$ can be made with Eqs. 1a and $1 \mathrm{~b}$ by calculating the mean $R^{2}$ of 1000 regressions of a single, randomly selected value

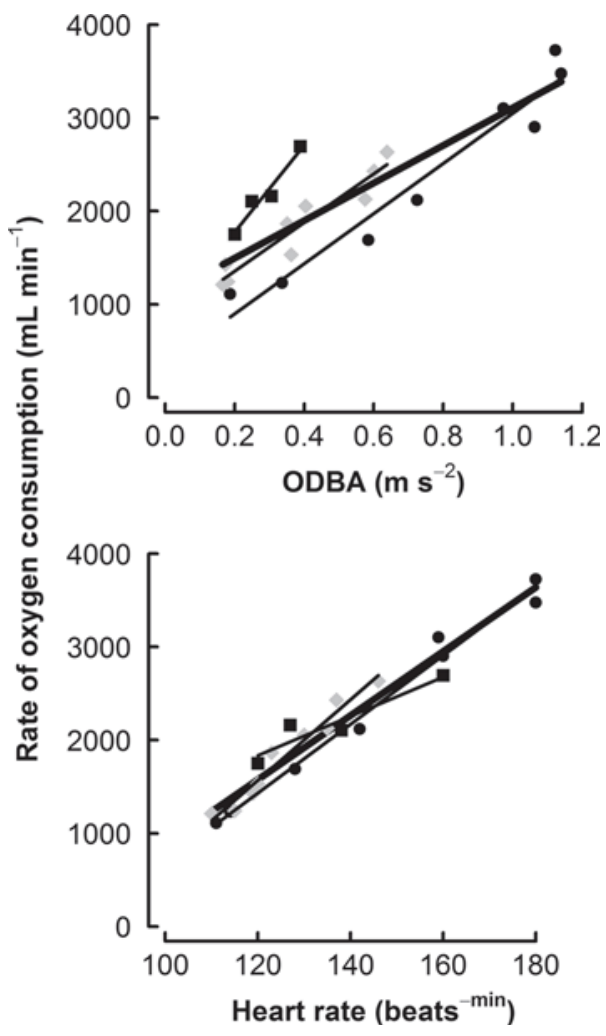

Fig. 2 Calibration data for a single participant in the calibration experiments. Circles represent treadmill walking, diamonds (in grey for clarity) represent pulling a fixed weight while treadmill walking to simulate man-hauling, and squares represent skiing on a cross-country ski machine of measured $\dot{V}_{\mathrm{O}_{2}}$ for each participant against predicted $\dot{V}_{\mathrm{O}_{2}}$ based on the associated proxy value. The mean $R^{2}$ value obtained using this method was $0.53( \pm 1$ SE: 0.01) and $0.46 \pm 0.01$ for Eqs. $1 \mathrm{a}$ and $1 \mathrm{~b}$, respectively, and $0.66 \pm 0.01$ and $0.65 \pm 0.01$ for Eqs. $2 \mathrm{a}$ and $2 \mathrm{~b}$, respectively; the relative comparison indicates that the inclusion of height substantially improves predictive power.

A measure of error associated with an estimate of mean $\dot{V}_{\mathrm{O}_{2}}$ for a group (or indeed an individual though such an estimate tends to be inaccurate due to inter-individual variation in the relationship between rate of energy expenditure and predictor variables; Green et al. 2001) derived from a prediction equation must account for the error inherent in the estimate (SEE). The SEE has a number of sources. To calculate SEE, specific information is required including data produced during the generation of the prediction equation. For the SEE to be calculated for estimates of $\dot{V}_{\mathrm{O}_{2}}$ from the prediction equations provided in the present study to estimate rate of energy expenditure during a range of typical Antarctic activities, the following values are required: number of individuals in the model used to generate the equation (for ODBA and for $f_{\mathrm{H}}$, respectively: $\left.n_{1}=12,14\right)$, number of data points in the model used to generate the equation $\left(n_{2}=216,252\right)$, variance estimate of participant ID as a random factor $\left(d^{2}=105,076,178,002\right)$, variance estimate of the error $\left(e^{2}=139,004,92,205\right)$, the mean value of ODBA or $f_{\mathrm{H}}$ used in the regression $(\bar{x}=0.455,117.9)$ and the sum of the squares of all the values of ODBA or $f_{\mathrm{H}}$ less mean ODBA or $f_{\mathrm{H}}\left(\sum\left(x_{k}-\bar{x}\right)^{2}\right.$, [mis-termed $\sum(x)^{2}$ in Green et al. 2001$]=18.188,176,406)$. These values also provide the activity-specific prediction equations presented in Table 2. For details about calculating an SEE for mean estimated $\dot{V}_{\mathrm{O}_{2}}$, refer to Green et al. (2001). Figure 3 provides simulations of the preciseness of predictions of $\dot{V}_{\mathrm{O}_{2}}$ of a group of people based on Eq. 1a, for different scenarios in terms of the number of people measured and the amount of data points collected.

\section{Field data}

The field acceleration data collected and analysed as part of the present study during the Antarctic expedition were recorded over a total of around $80 \mathrm{~h}$ and provided mean ODBA values for up to five people during the following
Table 1 Akaike's information criterion (AIC) and pseudo $R^{2}$ values for general linear models to generate rate of oxygen consumption $\left(\dot{V}_{\mathrm{O}_{2}}\right)$ prediction equations

\begin{tabular}{lllll}
\hline Equation & $n$ & $d f$ & AIC & $R^{2}$ \\
\hline$\dot{V}_{\mathrm{O}_{2}} \sim$ ODBA + participant ID & 221 & 4 & 3208.9 & 0.98 \\
$\dot{V}_{\mathrm{O}_{2}} \sim$ ODBA + participant ID + exercise type + ODBA $\times$ exercise type & 216 & 8 & 3173.9 & 0.98 \\
$\dot{V}_{\mathrm{O}_{2}} \sim f_{\mathrm{H}}+$ participant ID & 238 & 4 & 3654.0 & 0.78 \\
$\dot{V}_{\mathrm{O}_{2}} \sim f_{\mathrm{H}}+$ participant ID + exercise type $+f_{\mathrm{H}} \times$ exercise type & 238 & 8 & 3652.8 & 0.79 \\
\hline
\end{tabular}


Table 2 Prediction equations for individual activities, and the values associated with those equations required to calculate the accompanying SEEs

\begin{tabular}{|c|c|c|c|c|c|c|}
\hline Equation & $n_{1}$ & $n_{2}$ & $d^{2}$ & $e^{2}$ & $\bar{x}$ & $\overline{\sum\left(x_{k}-\bar{x}\right)^{2}}$ \\
\hline \multicolumn{7}{|l|}{ Walking } \\
\hline$\dot{V}_{\mathrm{O}_{2}}=(2443.4 \times$ ODBA +309.0$)+(23.5 \times$ height -4251.6$)$ & 12 & 66 & $36,343.2$ & $211,870.6$ & 0.616 & 8.579 \\
\hline $\begin{array}{l}\dot{V}_{\mathrm{O}_{2}}=\left(26.7 \times f_{\mathrm{H}}-1504.3\right)+(35.0 \times \text { height }-6037.5) \\
\text { Skiing }\end{array}$ & 13 & 76 & $193,523.5$ & $164,698.0$ & 123.1 & $89,127.5$ \\
\hline$\dot{V}_{\mathrm{O}_{2}}=(1259.5 \times \mathrm{ODBA}+1059.7)+(31.0 \times$ height -5494.7$)$ & 10 & 42 & $197,065.0$ & $34,036.9$ & 0.265 & 0.771 \\
\hline $\begin{array}{l}\dot{V}_{\mathrm{O}_{2}}=\left(13.1 \times f_{\mathrm{H}}-81.9\right)+(32.2 \times \text { height }-5519.0) \\
\text { Man-hauling }\end{array}$ & 11 & 45 & $152,544.9$ & $37,509.6$ & 118.0 & $19,043.0$ \\
\hline$\dot{V}_{\mathrm{O}_{2}}=(1993.2 \times$ ODBA +678.4$)+(30.2 \times$ height -5313.7$)$ & 11 & 108 & 120586.2 & $72,282.1$ & 0.433 & 5.550 \\
\hline$\dot{V}_{\mathrm{O}_{2}}=\left(23.7 \times f_{\mathrm{H}}-1152.2\right)+(36.2 \times$ height -6152.6$)$ & 14 & 131 & $137,945.6$ & $74,904.3$ & 114.5 & $64,957.0$ \\
\hline
\end{tabular}

In instances where participant heights are not available, the prediction equation is made viable by removing the second bracketed part $n_{1}=$ number of individuals in the model used to generate the equation; $n_{2}=$ number of data points in the model used to generate the equation; $d^{2}=$ variance estimate of participant ID as a random factor; $e^{2}=$ variance estimate of the error; $\bar{x}=$ mean value of ODBA or $f_{\mathrm{H}}$ used in the regression; $\sum\left(x_{k}-\bar{x}\right)^{2}=$ sum of the squares of all the values of ODBA or $f_{\mathrm{H}}$ less mean ODBA or $f_{\mathrm{H}}$

activities: walking, skiing, man-hauling, and work-related activities outside of the cabooses (Table 3). Based on these data, and applying the ODBA-based equations presented in Table 2 to the locomotion activities and Eq. $2 \mathrm{a}$ to the work-related activities, mean estimated $\dot{V}_{\mathrm{O}_{2}} \quad\left(\mathrm{~mL} \mathrm{O}_{2}\right.$ $\left.\min ^{-1}\right)$ for the members of the expedition team $( \pm 1 \mathrm{SEE})$ was as follows: walking, $1240.8 \pm 214$; skiing, $1495.9 \pm 352$; man-hauling, $1548.9 \pm 219$; working outside, $1088.5 \pm 198$.

\section{Discussion}

Previous studies investigating the energy costs of travel on the Antarctic continent or in other, sometimes similar environments have either employed the doubly labelled water technique and/or taken detailed records of food consumption in combination with mass change and changes in body composition (Stroud 1986, 1987; Sjodin et al. 1994; Stroud 1998; Fallowfield et al. 2014). Because food rations are typically pre-packed for such expeditions, in contrast to some other contexts (Hill and Davies 2001) monitoring food intake during these periods can be highly accurate, as of course can measures of body mass and composition (Acheson et al. 1980; Frykman et al. 2003), and thus in turn accurate estimates of long-term total energy expenditure can be calculated. However, while calibrated measures of ODBA or $f_{\mathrm{H}}$ also enable estimates of energy costs to be calculated for protracted periods of time, they are suitable for much shorter time scales as well.

Although calibrations for both ODBA and/or $f_{\mathrm{H}}$ are already available for walking (e.g. Halsey et al. 2008), calibrations of these proxies have not been published for cross-country skiing or man-hauling; two iconic modes of transport in Antarctica (despite some related work in this area on some types of skiing; Juhani et al. 1986; Tosi et al. 2010; Praz et al. 2014). Due to the particularly hostile environment of Antarctica, even with modern day equipment and technology, expeditions are physically and mentally arduous (Halsey and Stroud 2012). We provide here prediction equations for both ODBA and $f_{\mathrm{H}}$ such that they can be applied to quantify the energetics of both The Coldest Journey and of future expeditions in Antarctica and elsewhere.

\section{Estimates of energy expenditure during The Coldest Journey}

The prediction equations generated in the present study incorporating all activity types related well to $\dot{V}_{\mathrm{O}_{2}}$. Figure 3 indicates that, for example, in a situation where ODBA is measured in five individuals, with the data being averaged each day for a week the relative standard error of the estimate of $\dot{V}_{\mathrm{O}_{2}}$ for a typical mean value of ODBA of $0.4 \mathrm{~g}$ is about $13 \%$. The valuable implication here is that future Antarctic expeditions wishing to obtain an estimate of long-term energy expenditure for a chosen group need only record either accelerometry data or $f_{\mathrm{H}}$ from instrumented loggers; there is not a strong onus on detailing what exercise types were undertaken and when. However, where activity-specific energy expenditure is being investigated (as in the present study), the relevant specific prediction equations are provided (Table 2); their use will increase the preciseness of energy expenditure estimates, particularly in the case of ODBA (Fig. 2). These estimates will also be improved for averages of large expedition groups, and as always when proxies are used to estimate rate of energy expenditure caution should be taken when predicting for 

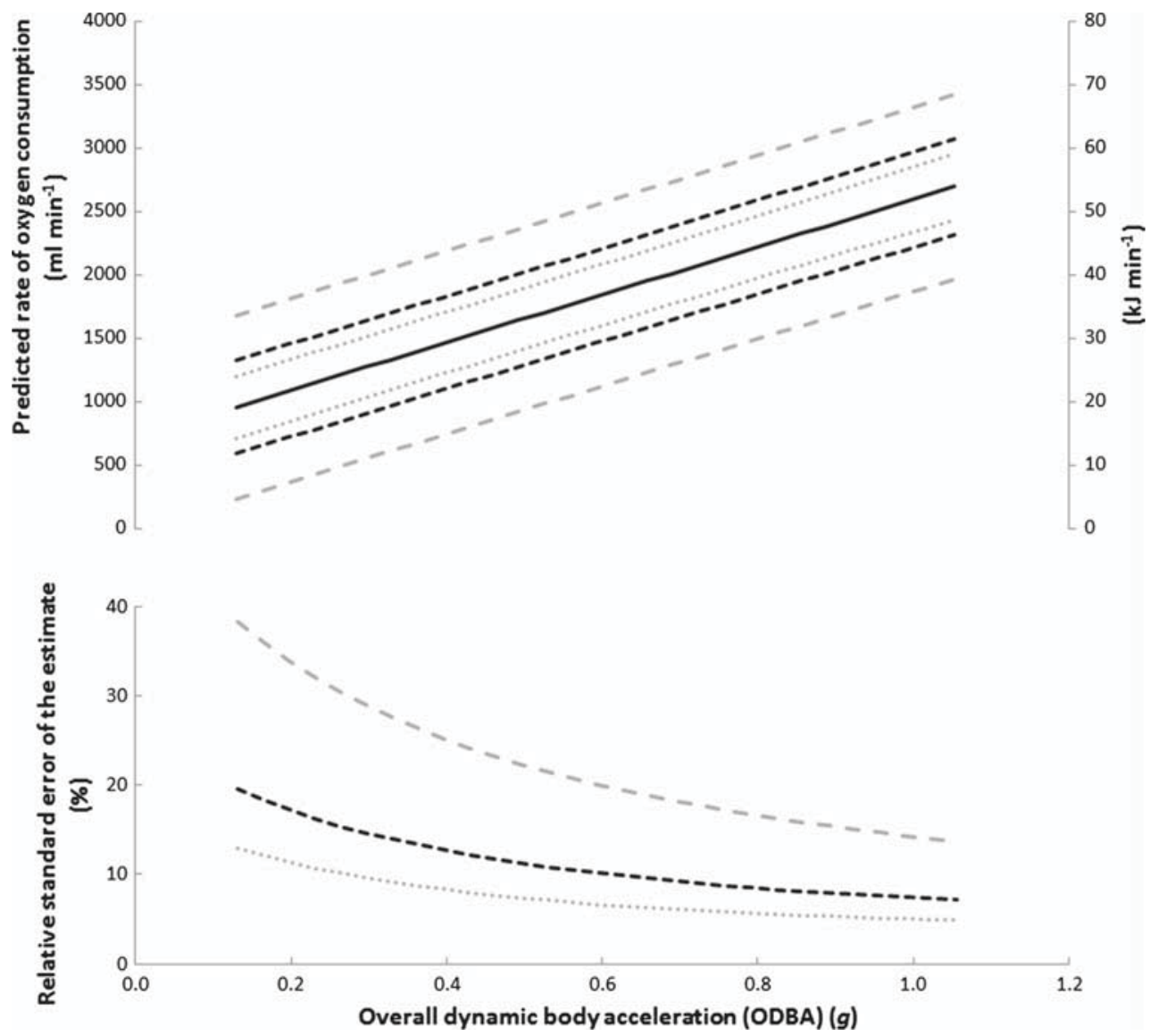

Fig. 3 Simulation demonstrating the preciseness of predictions of mean rate of energy expenditure (in both units of oxygen consumption and $\mathrm{kJ}$, per minute) from overall dynamic body acceleration (ODBA) for a group of people undertaking a relevant activity or activities during Antarctic expeditions, using prediction Eq. 1a. Three sampling scenarios are presented, and for each it is assumed that a mean is obtained per recording period and from those a mean is calculated per person, and then a grand mean calculated across individuals. The three scenarios are: (1) one ODBA value per day for one person, every day for a week; grey dashed lines, (2) one ODBA

single individuals since the associated SEEs will be large (Fig. 3; Green 2011).

The expedition team on The Coldest Journey were instructed to wear the accelerometry loggers whenever convenient, and where possible to note down their activities including timings. Sufficient data were obtained to present a proof of concept for the application of accelerometry data loggers under Antarctic conditions for estimating the energy expenditure of various activities. Activities were easily categorised into walking, skiing, man-hauling and miscellaneous work activities undertaken outside of the cabooses such as snow shovelling, refuelling and erecting/disassembling the vehicle tent. The estimated rate that energy was expended during man-hauling (31.1 $\mathrm{kJ} \mathrm{min}^{-1} ; 7.4 \mathrm{kcal} \mathrm{min}^{-1}$ ) was high and similar to that during skiing $\left(30.0 \mathrm{~kJ} \mathrm{~min}^{-1} ; \quad 7.2 \mathrm{kcal} \mathrm{min}^{-1}\right)$. value per day for five people, every day for a week; black dashed lines, (3) three ODBA values per day for 20 people, every day for a month; grey stippled lines. Effectively, scenarios (1) and (3) indicate the span of prediction preciseness to be expected from Eq. 1a, which is dependent on sample size (see main text for further details). Upper panel the $95 \%$ confidence intervals. The black solid line represents prediction Eq. 1a. Lower panel the relative standard error of the estimate (=standard error of the estimate/estimated rate of oxygen uptake $\times 100$ )

Previous expeditions and studies have reported that the details of ski equipment, skiing experience and the properties of the terrain underfoot can have a marked effect on the energy costs of this pursuit (Saibene et al. 1989; Preston 1999; Fiennes 2004). Both periods of skiing and manhauling on the journey seem to have been associated with a slightly higher rate of energy expenditure than was associated with walking $\left(24.9 \mathrm{~kJ} \mathrm{~min}^{-1} ; 6.0 \mathrm{kcal} \mathrm{min}^{-1}\right)$. This estimate of energy expenditure during walking is considerably higher than the measured energy costs for people walking at the same speed on concrete (around 2.4-fold greater; Lejeune et al. 1998), and is in fact similar to the cost for walking on sand (Lejeune et al. 1998). This high value is likely explained by factors such as a compliant and uneven substrate underfoot. It is likely that the difference in costs between man-hauling and walking are relatively 
Table 3 Mean \pm SD of overall dynamic body acceleration (ODBA) values for each of the five members of the team while undertaking a range of general categories of activity in Antarctica

\begin{tabular}{|c|c|c|c|c|c|}
\hline \multirow[t]{2}{*}{ Team member } & \multirow[t]{2}{*}{ Height $(\mathrm{cm})$} & \multicolumn{4}{|l|}{ ODBA $(g)$} \\
\hline & & Walking & Skiing & Man-hauling & Work outside \\
\hline A & 170 & & & 0.67 & 0.23 \\
\hline B & 170 & & & 0.42 & 0.25 \\
\hline $\mathrm{C}$ & 178 & 0.55 & 0.45 & 0.39 & 0.36 \\
\hline $\mathrm{D}$ & 173 & 0.32 & 0.33 & 0.46 & 0.36 \\
\hline $\mathrm{E}$ & 172 & 0.46 & & & 0.40 \\
\hline \multirow[t]{3}{*}{ Grand mean \pm SD } & & $0.44 \pm 0.11$ & $0.39 \pm 0.08$ & $0.49 \pm 0.1$ & $0.32 \pm 0.08$ \\
\hline & & \multicolumn{4}{|c|}{ Estimated $\dot{V}_{\mathrm{O}_{2}}\left(\mathrm{~mL} \min ^{-1}\right)$} \\
\hline & & $1240.8 \pm 21$ & $1495.9 \pm 352.1$ & $1548.9 \pm 218.8$ & $1088.5 \pm 198.1$ \\
\hline
\end{tabular}

Estimated mean $\dot{V}_{\mathrm{O}_{2}} \pm$ SEE for the team for each activity category are also presented, calculated from equations in Table 2, and from Eq. 2a for 'work outside'

small at least in part because of the slower average paces during the former as a result of pulling the pulk (pers. obs.). Furthermore, previous research has shown that pulling a weighted sled is a relatively efficient way of transporting a load (Juhani et al. 1986). All of these modes of transportation, particularly skiing and man-hauling, expended energy at a somewhat higher rate than the nonetheless high rate of energy expenditure during general outdoor work $\left(21.9 \mathrm{~kJ} \mathrm{~min}^{-1} ; 5.2 \mathrm{kcal} \mathrm{min}^{-1}\right)$, which was undertaken during periods of consolidation along the journey.

\section{Assessing the validity of the accelerometry data}

Arctic and Antarctic expeditions for which overall energy expenditures have been estimated have involved a divided day: about $50 \%$ man-hauling and $50 \%$ resting or undertaking low-level activities. Typical daily energy expenditure in such cases averages around $30 \mathrm{MJ}$ day $^{-1}$ (7000 kcal day ${ }^{-1}$ ) (Stroud 1987; Stroud et al. 1993; Stroud 1998). Similar daily energy expenditures are reported for cross-country skiers during training (Sjodin et al. 1994). Man-hauling for $12 \mathrm{~h}$ a day at $7.4 \mathrm{kcal} \mathrm{min}^{-1}$ would expend around $5300 \mathrm{kcal}$, while sleeping, resting and low-level activities over $12 \mathrm{~h}$ probably expends a little over $1000 \mathrm{kcal}^{-1}$, and thus there is good agreement in the estimates obtained between these various studies and the present study, providing broad-scale validation of the calibrations.

Calibrated proxies for energy expenditure may sometimes provide reduced accuracy under certain circumstances, for example when there are differences between laboratory and field conditions. Important factors include the substrate underfoot (Pandolf et al. 1976), the substrate gradient and wind speed, but only if the resultant differences in energy expenditure are not associated with changes in the proxy values as described by the calibration curves. Comparisons of the activity-specific estimates obtained in the present study are similar to measured values in previous studies, for example Juhani et al. (1986) reported a mean $\dot{V}_{\mathrm{O}_{2}}$ in soldiers skiing at $3.6 \mathrm{~km} \mathrm{~h}^{-1}$ of $1.2 \mathrm{~L} \mathrm{~min}^{-1}$, while in the present study mean skiing speed was $3.7 \mathrm{~km} \mathrm{~h}^{-1}$ and estimated $\dot{V}_{\mathrm{O}_{2}}$ was $1.5 \mathrm{~L} \mathrm{~min}^{-1}$. Vanderbie (1956) reported that man-hauling expended around $33 \mathrm{~kJ} \mathrm{~min}^{-1}$ at $4 \mathrm{~km} \mathrm{~h}^{-1}$ and a pulling force of $80 \mathrm{~N}$ while in the present study mean man-hauling speed averaged $3.3 \mathrm{~km} \mathrm{~h}^{-1}$ and estimated rate of energy expenditure was $31 \mathrm{~kJ} \mathrm{~min}^{-1}$. These concurring sets of results provide some validation for the present study calibrations over shorter timescales.

Accelerometry would not be expected to perform well as a predictor of energy expenditure during periods of inactivity; however, resting metabolic rates, for example during sleep, can still be veritably estimated by other means, e.g. from body mass (Heymsfield et al. 1997). Furthermore, as highlighted on The Coldest Journey, Antarctic expeditions are epitomised by prolonged days of physical effort, and during these periods accelerometry data can excel as an energy proxy. Indeed, the calibration data obtained in the present study indicate that during activity, ODBA provides at least as strong relationships with $\dot{V}_{\mathrm{O}_{2}}$ as does $f_{\mathrm{H}}$, as has been demonstrated previously for walking (Halsey et al. 2008). Also, while accelerometry may not fully account for increases in metabolic rate due to cold ambient temperatures (van Ooijen et al. 2004; Green et al. 2009), in contrast to the often ill-equipped expeditions of the 'Golden Age' of Antarctic exploration (Halsey and Stroud 2011) the metabolic rate of modern explorers is probably little affected by low temperatures because the combination of activity-related heat production and the use of high-technology clothing keeps the microclimate around their skin within the thermo-neutral zone (Færevik et al. 2001). Indeed, the expedition team in the present study reported being consistently warm while outside the cabooses. Thus, not only 
do accelerometers represent robust, easy-to-use devices even under difficult conditions, as demonstrated here, but they can veritably be used to estimate long-term or daily energy costs as well as short-term, activity-specific costs, at least when environmental conditions have been reasonably well matched by the laboratory conditions of the calibrations. We therefore hope that future expeditions to Antarctica will consider the use of data loggers measuring either $f_{\mathrm{H}}$ or body acceleration, to which they can apply the prediction equations provided in the present study.

\section{Final word}

Antarctic adventurers continue to explore the continent, often with limited food supplies and restricted transport options. Further progression of our understanding about the energy expended during such expeditions will be valuable in planning logistics and health monitoring during presentday excursions as well as understanding the limitations, sometimes lethal, of the journeys undertaken by the pioneers of Antarctic exploration a century ago. The use of calibrated data loggers on future explorations is likely to be central to these endeavours.

Acknowledgments We are grateful to the 14 participants involved in the calibration experiments for their time, and to Tom Reeve and Alison Carlisle who provided invaluable technical assistance during data collection. This study was inspired by The Coldest Journey expedition (http://www.thecoldestjourney.org/), which undertook a scientific programme entitled The White Mars Project.

Authors' contributions LH, AK and MS conceived of the study, LH designed the experiments and analysed the data, and LH, RL, AK and MS coordinated the study. LH, PC, AN and CO carried out the laboratory experiments, while RL carried out the field experiments. LH drafted the manuscript, with input from co-authors. All authors gave final approval for publication.

\section{Compliance with ethical standards}

Ethical approval All procedures performed in studies involving human participants were in accordance with the ethical standards of the institutional and/or national research committee and with the 1964 Declaration of Helsinki and its later amendments or comparable ethical standards.

\section{References}

Acheson KJ, Campbell IT, Edholm OG, Miller DS, Stock MJ (1980) A longitudinal study of body weight and body fat changes in Antarctica. Am J Clin Nutr 33:972-977

Achten J, Gleeson M, Jeukendrup A (2002) Determination of the exercise intensity that elicits maximal fat oxidation. Med Sci Sports Exerc 34:92-97

ACSM (2013) American College of Sports Medicine's guidelines for exercise testing and prescription. Lippincott Williams \& Wilkins, Philadelphia, USA
Barton K (2013) MuMIn: Multi-model inference. R package version 1.9.13

Boothby W (1915) A determination of the circulation rate in man at rest and at work. Am J Physiol 37:383-417

Bouchard D, Trudeau F (2008) Estimation of energy expenditure in a work environment: comparison of accelerometry and oxygen consumption/heart rate regression. Ergonomics 51:663-670

Burnham KP, Anderson DR (2010) Model selection and multi-model inference: a practical information-theoretic approach, 2nd edn. Springer, New York

Carroll D, Turner JR, Prasad R (1986) The effects of level of difficulty of mental arithmetic challenge on heart rate and oxygen consumption. Int J Psychophysiol 4:167-173

Cavagna GA, Saibene F, Margaria R (1963) External work in walking. J Appl Physiol 18:1-9

Chilibeck PD, Paterson DH, Petrella RJ, Cunningham DA (1996) The influence of age and cardiorespiratory fitness on kinetics of oxygen uptake. Can J Appl Physiol 21:185-196. doi:10.1139/ h96-015

Eston R, Rowlands A, Ingledew D (1998) Validity of heart rate, pedometry, and accelerometry for predicting the energy cost of children's activities. J Appl Physiol 84:362-371

Færevik H, Markussen D, Øglænd G, Reinertsen R (2001) The thermoneutral zone when wearing aircrew protective clothing. J Therm Biol 26:419-425

Fallowfield JL et al (2014) Energy expenditure, nutritional status, body composition and physical fitness of Royal Marines during a 6-month operational deployment in Afghanistan. $\mathrm{Br} \mathrm{J}$ Nutr 112:821-829. doi:10.1017/S0007114514001524

Fiennes R (2004) Race to the pole: tragedy, heroism, and Scott's Antarctic quest. Hyperion, New York

Frykman P, Harman E, Opstad P, Hoyt R, DeLany J, Friedl K (2003) Effects of a 3-month endurance event on physical performance and body composition: the G2 trans-greenland expedition. Wilderness Environ Med 14:240-248

Gleiss AC, Wilson RP, Shepard ELC (2011) Making overall dynamic body acceleration work: on the theory of acceleration as a proxy for energy expenditure. Methods Ecol Evol 2:23-33

Green J (2011) The heart rate method for estimating metabolic rate: review and recommendations. Comp Biochem Physiol Part A 258:287-304

Green JA, Butler PJ, Woakes AJ, Boyd IL, Holder RL (2001) Heart rate and rate of oxygen consumption of exercising macaroni penguins. J Exp Biol 204:673-684

Green J, Halsey LG, Wilson RP, Frappell PB (2009) Estimating energy expenditure of animals using the accelerometry technique: activity, inactivity and comparison with the heart-rate technique. J Exp Biol 212:471-482

Halsey L (2011) The challenge of measuring energy expenditure: current field and laboratory methods. Comp Biochem Physiol Part A 158:247-251. doi:10.1016/j.cbpa.2011.01.001

Halsey L, Stroud M (2011) Could Scott have survived with today's physiological knowledge? Curr Biol 21:R457-R461. doi:10. 1016/j.cub.2011.04.015

Halsey LG, Stroud M (2012) 100 years since Scott reached the pole: a century of learning about the physiological demands of Antarctica. Physiol Rev 92:521-536. doi:10.1152/physrev.00031.2011

Halsey LG, Fahlman A, Handrich Y, Schmidt A, Woakes AJ, Butler PJ (2007) How accurately can we estimate energetic costs in a marine top predator, the king penguin? Zoology 110:81-92

Halsey L, Shepard E, Hulston C, Venables M, White C, Jeukendrup A, Wilson R (2008) Acceleration versus heart rate for estimating energy expenditure and speed during locomotion in animals: tests with an easy model species. Homo Sapiens Zool 111:231-241 
Halsey LG, Green AJ, Wilson R, Frappell PB (2009a) Accelerometry to estimate energy expenditure during activity: best practice with data loggers. Phys Biochem Zool 82:396-404

Halsey LG, Shepard E, Gomez Laich A, Quintana F, Green JA, Wilson RP (2009b) The relationship between oxygen consumption and body acceleration in a range of species. Comp Biochem Physiol Part A 152:197-202

Halsey L, Shepard E, Wilson R (2011) Assessing the development and application of the accelerometry technique for estimating energy expenditure. Comp Biochem Physiol A 158:305-314

Heymsfield S, Childers D, Beetsch J, Allison D, Pietrobelli A (1997) Body size and human energy requirements: reduced massspecific resting energy expenditure in tall adults. J Appl Physiol 103:1543-1550

Hill RJ, Davies PSW (2001) The validity of self-reported energy intake as determined using the doubly labelled water technique. Br J Nutr 85:415-430. doi:10.1079/BJN2000281

Juhani I, Pekka S, Timo A (1986) Strain while skiing and hauling a sledge or carrying a backpack. Eur J Appl Physiol 55:597-603. doi:10.1007/bf00423203

Lejeune TM, Willems PA, Heglund NC (1998) Mechanics and energetics of human locomotion on sand. J Exp Biol 201:2071-2080

Lyons GN, Halsey LG, Pope EC, Eddington J, Houghton JDR (2013) Energy expenditure during activity in the American lobster Homarus americanus: correlations with body acceleration. Comp Biochem Physiol A 166:278-284. doi:10.1016/j.cbpa. 2013.06.024

Marshall E (1943) Antarctic episode, vol 8. The Medical Press and Circular, London

Meijer GA, Westerterp KR, Koper H, Hoor FT (1989) Assessment of energy expenditure by recording heart rate and body acceleration. Med Sci Sports Exerc 21:343-347

Pandolf KB, Haisman M, Goldman RF (1976) Metabolic energy expenditure and terrain coefficients for walking on snow. Ergonomics 19:683-690

Pinheiro J, Bates D, DebRoy S, Sarkar D, Team RC (2014) nlme: linear and nonlinear mixed effects models

Praz C, Léger B, Kayser B (2014) Energy expenditure of extreme competitive mountaineering skiing. Eur J Appl Physiol 114:2201-2211

Preston D (1999) A first rate tragedy. Houghton Mifflin Company, Boston

R Development Core Team (2013) R: a language and environment for statistical computing. R Foundation for Statistical Computing, Vienna, Austria. http://www.R-project.org

Saibene F, Cortili G, Roi G, Colombini A (1989) The energy cost of level cross-country skiing and the effect of the friction of the ski. Eur J Appl Physiol 58:791-795. doi:10.1007/bf00637393
Schmidt-Nielsen K (1997) Energy metabolism. In: Schmidt-Nielsen K (ed) Animal physiology, 5th edn. Cambridge University Press, Cambridge, pp 169-214

Scott R (2008) Journals: Captain Scott's last expedition Oxford World's Classics. OUP, Oxford

Sjodin A, Andersson A, Hogberg J, Westerterp KR (1994) Energy balance in cross-country skiers: a study using doubly labeled water. Med Sci Sports Exerc 26:720-724

Stroud M (1986) Scott: 75 years on. Br Med J 293:1652-1653

Stroud M (1987) Nutrition and energy balance on the 'Footsteps of Scott' expedition 1984-86. Hum Nutr Appl Nutr 41A:426-433

Stroud M (1993) Shadows on the wasteland. The Overlook Press, Woodstock

Stroud M (1998) The nutritional demands of very prolonged exercise in man. Proc Nutr Soc 57:55-61

Stroud M, Coward W, Sawyer M (1993) Measurements of energy expenditure using isotope-labelled water $\left({ }^{2} \mathrm{H}_{2}{ }^{18} \mathrm{O}\right)$ during an Arctic expedition. Eur J Appl Physiol 67:375-379

Stroud M, Jackson A, Waterlow J (1996) Protein turnover rates of two human subjects during an unassisted crossing of Antarctica. Br J Nutr 76:165-174

Stroud M, Ritz P, Coward W, Sawyer M, Constantin-Teodosiu D, Greenhaff PL, Macdonald I (1997) Energy expenditure using isotope-labelled water $\left({ }^{2} \mathrm{H}_{2}{ }^{18} \mathrm{O}\right)$, exercise performance, skeletal muscle enzyme activities and plasma biochemical parameters in humans during 95 days of endurance exercise with inadequate energy intake. Eur J Appl Physiol 76:243-252

Terrier P, Aminian K, Schutz Y (2001) Can accelerometry accurately predict the energy cost of uphill/downhill walking? Ergonomics 44:48-62

Tosi P, Leonardi A, Zerbini L, Rosponi A, Schena F (2010) Energy cost and efficiency of ski mountaineering. A laboratory study. J Sports Med Phys Fit 50:400

van Ooijen AMJ, van Marken Lichtenbelt WD, van Steenhoven AA, Westerterp KR (2004) Seasonal changes in metabolic and temperature responses to cold air in humans. Physiol Behav 82:545-553. doi:10.1016/j.physbeh.2004.05.001

Vanderbie JH (1956) Metabolic cost of simulated sled pulling on the treadmill. Res Q Am Assoc Health Phys Educ Recreat 27:111-116

Whipp B, Wasserman W (1972) Oxygen uptake kinetics for various intensities of constant-load work. J Appl Physiol 33:351-356

Wilson R, White C, Quintana F, Halsey L, Liebsch N, Martin G, Butler PJ (2006) Moving towards acceleration for estimates of activity-specific metabolic rate in free-living animals: the case of the cormorant. J Anim Ecol 75:1081-1090 